\title{
Plasma monitoring and PECVD process control in thin film silicon-based solar cell manufacturing
}

\author{
Onno Gabriel ${ }^{1, a}$, Simon Kirner ${ }^{1}$, Michael Klick ${ }^{2}$, Bernd Stannowski ${ }^{1}$, and Rutger Schlatmann ${ }^{1}$ \\ 1 PVcomB, Helmholtz-Zentrum Berlin für Materialien und Energie GmbH, Schwarzschildstr. 3, 12489 Berlin, Germany \\ 2 Plasmetrex GmbH, Schwarzschildstr. 3, 12489 Berlin, Germany
}

Received: 30 July 2013 / Received in final form: 12 November 2013 / Accepted: 10 December 2013

Published online: 5 February 2014

(C) Gabriel et al., published by EDP Sciences, 2014

\begin{abstract}
A key process in thin film silicon-based solar cell manufacturing is plasma enhanced chemical vapor deposition (PECVD) of the active layers. The deposition process can be monitored in situ by plasma diagnostics. Three types of complementary diagnostics, namely optical emission spectroscopy, mass spectrometry and non-linear extended electron dynamics are applied to an industrial-type PECVD reactor. We investigated the influence of substrate and chamber wall temperature and chamber history on the PECVD process. The impact of chamber wall conditioning on the solar cell performance is demonstrated.
\end{abstract}

\section{Introduction}

Plasma-enhanced chemical vapor deposition (PECVD) of thin film silicon is a key process in various industrial applications. Thin film silicon material is used in flat panel displays [1], as passivation layers in crystalline silicon and hetero junction solar cells $[2,3]$, and as absorber layers in thin film silicon-based solar cells and modules [4-7]. The material can be deposited by means of plasma-enhanced chemical vapor deposition (PECVD) in two different allotropes: hydrogenated amorphous $(\mathrm{a}-\mathrm{Si}: \mathrm{H})$ and microcrystalline $(\mu \mathrm{c}-\mathrm{Si}: \mathrm{H})$ silicon. Both types of materials are generally deposited using process gas mixtures of silane $\left(\mathrm{SiH}_{4}\right)$ and hydrogen $\left(\mathrm{H}_{2}\right)$, but with differences in the process conditions such as the gas flow composition, chamber pressure and RF power density $[4,8]$. Both types are applied in silicon-based tandem device solar cells $[5,7]$, where the intrinsic (i) layer of the top cell is made from a-Si:H, while the $i$-layer of the bottom cell is made from $\mu \mathrm{c}-\mathrm{Si}: \mathrm{H}$ material. Another photovoltaic application is the hetero junction solar cell, where thin layers of a-Si:H are deposited on crystalline silicon wafers as passivation layers [2]. Doped $p$ - and $n$-layers can be deposited by small admixtures of doping gases such as $\mathrm{B}\left(\mathrm{CH}_{3}\right)_{3}$ or $\mathrm{PH}_{3}$ to the $\mathrm{SiH}_{4} / \mathrm{H}_{2}$ process gas mixture. Moreover, the refractive index and the electronic band gap and, thus, the optical absorption of the material can be varied by alloying of the material with carbon and oxygen, e.g. by the admixture of $\mathrm{CH}_{4}$ or $\mathrm{CO}_{2}$ to the process gas [9-13]. Due to the

\footnotetext{
${ }^{a}$ e-mail: onno.gabriel@helmholtz-berlin.de
}

wide spread and large variety of applications of these films the growth mechanism of thin film silicon is the topic of ongoing research.

The plasma parameters determining the thin film growth remain mostly unknown. Insights into the plasma chemistry and the plasma-surface interaction, including thin film growth can generally be obtained by means of in situ plasma diagnostics. These diagnostics directly reveal the plasma parameters such as gas phase composition, electron and ion densities, energy distributions and temperatures. All these plasma parameters influence the growth process directly and, thereby, the properties of the resulting thin films as well. Each property is usually detected by a special diagnostic technique, each with its advantages and limitations. Among the plasma diagnostics proven to be useful for investigations of thin film silicon growth are optical emission spectroscopy (OES) [14-17], laser-induced fluorescence (LIF) [14, 18], Fourier-transform infra-red spectroscopy (FTIR) [16, 19], tunable diode laser absorption spectroscopy (TDLAS) [20, 21], quadrupole mass spectrometry (QMS) [15, 22, 23], or cavity ring down spectroscopy (CRDS) [24]. Measurements of the electron density and the dynamics of electrons in the plasma gas phase, however, remain challenging under PECVD conditions.

An often neglected but relevant impact on the plasma chemistry is the influence of previously deposited films on substrate, electrode and chamber walls, which results in released atoms and molecules into the plasma by surface etching and surface association processes $[25,26]$. Although chamber wall conditioning by the deposition of 
a defined layer prior to the actual thin film deposition is a well-established method to prevent an unpredictable influence of the reactor wall condition on the film quality, the actual influence of the chamber wall condition on the plasma chemistry is an often unknown parameter. Atoms, radicals and molecules are not only lost to surfaces surrounding the active plasma zone, but are also released from these surfaces even under deposition conditions. They can have a strong impact on the plasma chemistry. For example, in hydrogen rich a-Si:H or $\mu \mathrm{c}-\mathrm{Si}: \mathrm{H}$ deposition regimes, the flow rate of $\mathrm{SiH}_{4}$ molecules and $\mathrm{SiH}_{x}$ radicals originating from recombination and etch processes from the surfaces back into the plasma gas phase can be a substantial fraction of the total $\mathrm{SiH}_{4}$ process gas flow into the reactor [17]. The properties and structure of a chamber wall conditioning layer influences the deposition process, as we will show for the $\mu \mathrm{c}-\mathrm{Si}: \mathrm{H}$ deposition process. Moreover, pre-treatments of conditioning layers or of previously deposited layers on the substrate itself can be beneficial for the layer quality, e.g. by $\mathrm{H}_{2}$ or $\mathrm{CO}_{2}$ plasma treatment to improve the start of the $\mu \mathrm{c}-\mathrm{Si}: \mathrm{H}$ growth process $[27,28]$. Additionally, plasma treatments are used for chamber cleaning [29] or to improve the interface properties between two different layers [30].

In this paper we present results of our research regarding plasma-surface interactions during PECVD processes used for thin film silicon deposition. We focus on three different in situ plasma diagnostics, which can readily be applied to an industrial-type PECVD process chamber, namely optical emission spectroscopy (OES), residual gas analysis/mass spectrometry (MS) and a novel technique called non-linear enhanced electron dynamics (NEED). The applied diagnostics deliver detailed and complementary information on the plasma chemistry. We will give examples - measured in experiments and also during solar cell production - how chamber walls and the properties of the surface material influences plasma chemistry during PECVD and how these changes in plasma chemistry influence the material properties and, thus, the resulting solar cell performance.

\section{Experiment}

All thin film silicon layer depositions were performed in an Applied Materials AKT 1600A cluster tool consisting of three PECVD process chambers connected to a central transfer chamber (Fig. 1) [13]. Up to six glass substrates of $30 \times 30 \mathrm{~cm}^{2}$ area were loaded via a load lock to a storage chamber. These substrates were automatically transferred by a central substrate mover from the storage via the transfer chamber to the PECVD process chambers, where the $p-i-n / p-i$-n layer structure of a-Si:H/ $\mu$ c-Si:H tandem solar cells were deposited. Software, process control and PECVD plasma conditions are very similar to those of the larger AKT 60k cluster tools used in industry to manufacture solar modules and flat panel displays of up to $220 \times 260 \mathrm{~cm}^{2}$ area (Gen8.5).

Within the PECVD chambers a shower head electrode ("diffuser") is mounted in the chamber top cover and

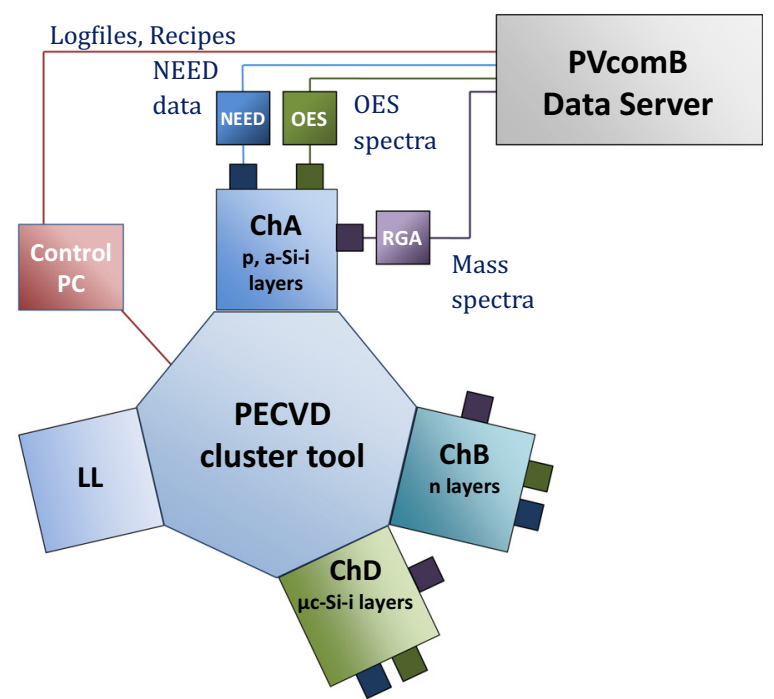

Fig. 1. Scheme of the AKT 1600A PECVD cluster, plasma diagnostics tools and the data management structure at PVcomB.

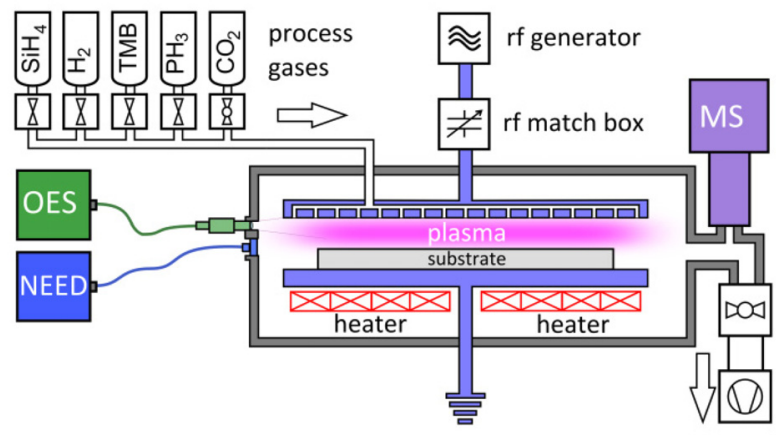

Fig. 2. Scheme of the process chamber with the parallel plate PECVD reactor and the three plasma diagnostics OES, MS and NEED.

powered by a $13.56 \mathrm{MHz}$ radio frequency $(\mathrm{RF})$ generator with RF powers between some $10 \mathrm{~W}$ and $1000 \mathrm{~W}$ (Fig. 2). Process gases flow into the chamber through the shower head electrode. The glass substrate is located on the grounded electrode ("susceptor"), which is heated up to typically $200{ }^{\circ} \mathrm{C}$. All chamber walls are heated to $80^{\circ} \mathrm{C}$. The susceptor is movable in vertical direction and allows a variable electrode spacing from 5 to $75 \mathrm{~mm}$. PECVD processes were performed typically at pressures in the range 200-1300 Pa with total gas flows rates between some $100 \mathrm{sccm}$ up to $10000 \mathrm{sccm}$. The chambers are usually cleaned after each layer deposition using a $\mathrm{NF}_{3} / \mathrm{Ar}$ etch plasma followed by the deposition of a thin silicon layer ("conditioning layer") to ensure stable and reproducible process start conditions and reduce contamination. Amorphous and microcrystalline layers were deposited using process gas mixtures of $\mathrm{SiH}_{4}$ and $\mathrm{H}_{2}$. Doping of both materials is achieved by the admixture of trimethylboron, $\mathrm{B}\left(\mathrm{CH}_{3}\right)_{3}$ or $\mathrm{TMB}$, to the $\mathrm{SiH}_{4} / \mathrm{H}_{2}$ process gas mixture (resulting in $p$-layers) or phosphine, $\mathrm{PH}_{3}$ (resulting to $n$-layers). Silicon alloys were deposited using an admixture 
O. Gabriel et al.: Plasma monitoring and PECVD process control in thin film silicon-based solar cell manufacturing

Table 1. Wavelengths of line and band transitions of electronically excited atoms, radicals and molecules detected by OES during a-Si:H/ $\mu \mathrm{c}-\mathrm{Si}: \mathrm{H}$ deposition and $\mathrm{Ar} / \mathrm{NF}_{3}$ plasma chamber cleaning.

\begin{tabular}{ccc}
\hline Species & Transition & Wavelength \\
\hline $\mathrm{Si}$ & $3 s^{2} 3 p^{2}{ }^{1} \mathrm{D} 2-s^{2} 3 p 4 s^{1} \mathrm{P}^{\circ} 1$ & $288.3 \mathrm{~nm}$ \\
$\mathrm{SiH}$ & $\mathrm{X}^{2} \Pi-\mathrm{A}^{2} \Delta$ band & $409-422 \mathrm{~nm}$ \\
$\mathrm{H}$ & $n=3-n=2$ ("Balmer $\left.\mathrm{H}_{\alpha} "\right)$ & $656.3 \mathrm{~nm}$ \\
$\mathrm{H}$ & $n=4-n=2$ ("Balmer $\mathrm{H}_{\beta}$ ") & $486.1 \mathrm{~nm}$ \\
$\mathrm{H}_{2}$ & $2 s^{3} \Sigma_{g}^{+}-3 p^{3} \Pi_{u}^{-}$band ("Fulcher- $\alpha$ ") & $570-640 \mathrm{~nm}$ \\
$\mathrm{~F}$ & $2 s^{2} 2 p^{4}\left({ }^{3} \mathrm{P}\right) 3 s^{2} \mathrm{P}^{3} / 2-2 s^{2} 2 p^{4}\left({ }^{3} \mathrm{P}\right) 3 p^{2} \mathrm{P}^{\circ} 3 / 2$ & $703.7 \mathrm{~nm}$ \\
$\mathrm{Ar}$ & $3 s^{2} 3 p^{4}\left({ }^{3} \mathrm{P}\right) 4 s^{2} \mathrm{P}^{1} / 2-3 s^{2} 3 p^{4}\left({ }^{3} \mathrm{P}\right) 4 p^{2} \mathrm{D}^{\circ} 3 / 2$ & $496.5 \mathrm{~nm}$ \\
\hline
\end{tabular}

of $\mathrm{CH}_{4}$, resulting in $\mathrm{SiC}_{x}: \mathrm{H}$ films, or of $\mathrm{CO}_{2}$, resulting in $\mathrm{SiO}_{x}: \mathrm{H}$ films.

The deposition process conditions were monitored by means of optical emission spectroscopy (OES), mass spectrometry (MS) and by an electrodynamics- and model-based technique called non-linear electron dynamics (NEED) (see Fig. 2). OES and MS do not depend on any assumption about the plasma. The missing link to the plasma physics can be provided by NEED (see Sect. 2.3), which is based on a discharge model and provides a series resonance frequency, in first order depending on the electron density in the plasma, and the RF resistivity of the plasma, which is proportional to the quotient of collision rate for momentum transfer and electron density. Both parameters are provided at an absolute scale. The time resolution of the plasma diagnostics is about $1 \mathrm{~s}$, while the data for chamber pressure, gas flow rates, RF power, temperatures, etc. are recorded with $0.25 \mathrm{~s}$ time resolution. All data from plasma diagnostics and AKT process data are stored in a central data base allowing user access to all recorded data, including data visualization and analysis.

\subsection{Optical emission spectroscopy (OES)}

One of the easiest applied in situ plasma diagnostics is OES. Only one transparent window port is needed to measure the emission spectrum generated by excited species in the plasma $[4,17]$. On the other hand, the interpretation of measured spectra is more difficult and results often in indirect and relative properties of the plasma $[15,16]$. The measured intensity $I_{\prime \prime}^{\prime \prime}$ of an emission line ("peak") in a spectrum depends not only on the transition probability $A_{\prime \prime}^{\prime}$ between the upper (') and lower (") electronic state of the transition, but also on the density of atoms or molecules in the upper electronic state $N_{1}$ :

$$
I_{\prime \prime}^{\prime} \sim A_{\prime \prime}^{\prime} N_{\prime} .
$$

The upper state is generally populated by excitation processes due to collisions of electrons with atoms and molecules, which are nearly all in the electronic ground state. Therefore, $N$, depends not only on the ground state density of an atom or molecule, but also on the electron density and the electron energy distribution function (EEDF). In more complicated cases, the upper state

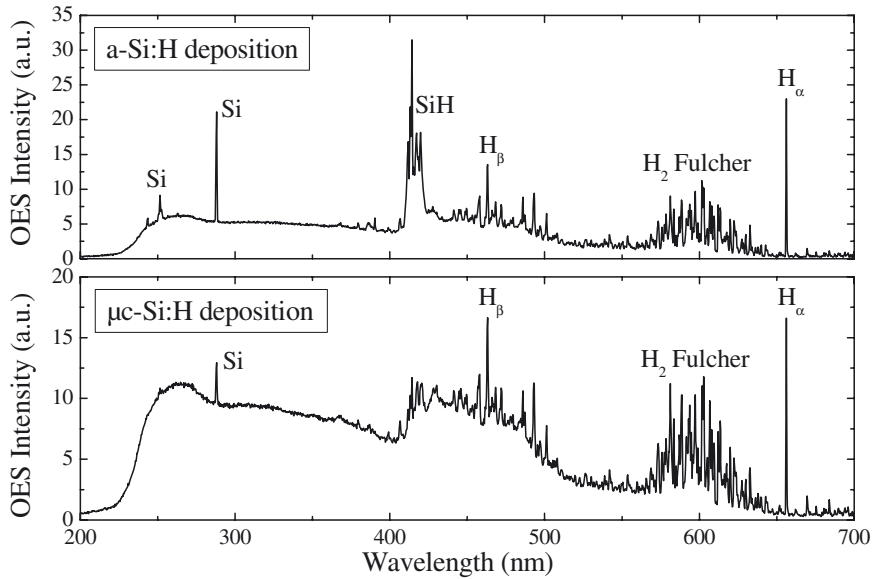

Fig. 3. Optical emission spectra measured during the deposition of amorphous (top) and microcrystalline thin film silicon (bottom). Some prominent optical emission peaks and band structures are labelled.

is populated additionally by other processes such as deexcitation from even higher states or gas phase reactions such as dissociative attachment. A full interpretation of measured spectra can only be given by detailed collisionalradiative models [15], which take all these reactions and transitions into account. Such a model is beyond the scope of this contribution.

From an experimental point of view, problems arise from the spatial distribution of the light emission from the plasma, which is usually higher in the plasma bulk and lower at the surroundings, e.g. near the substrate or electrodes (plasma sheaths). Moreover, the thickness of the plasma sheaths depend strongly on process conditions such as the chamber pressure. Therefore, a measured spectrum always depends on the optics and view direction into the chamber, i.e. the integral over the full line of sight through the plasma zone. We measured optical emission spectra using a fiber optics coupled directly to a quartz window. The same fiber window mount is installed on all three process chambers allowing exactly the same integrated views into the plasma. The light is coupled via a fiber into a two channel AvaSpec-2048 spectrometer by Avantes. The most important measured peaks and bands appearing during our PECVD processes are listed in Table 1. Example spectra during a-Si:H and $\mu \mathrm{c}-\mathrm{Si}: \mathrm{H}$ deposition are shown in Figure 3. Figure 4 shows measured 

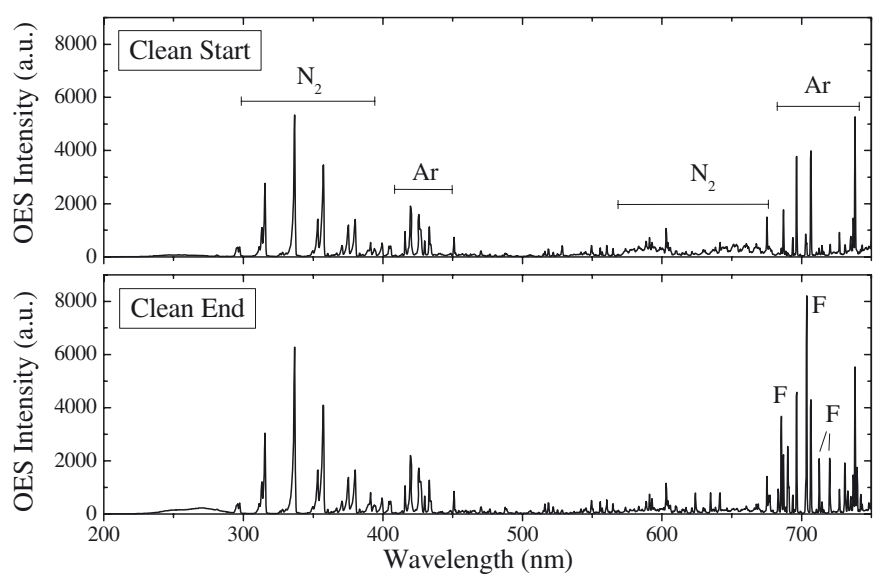

Fig. 4. Optical emission spectra measured during chamber cleaning in an $\mathrm{Ar} / \mathrm{NF}_{3}$ etch plasma. The clean/etch start is shown on top and the end on the bottom of the figure. F line intensities increase after the end point of the etching process.

spectra during the start and end of an $\mathrm{Ar} / \mathrm{NF}_{3}$ plasma etch for chamber cleaning. The intensities of emission peaks from $\mathrm{F}$ atoms increase strongly after the end point of the etching process, because $\mathrm{F}$ is not consumed anymore by the etching process, which lead to the formation of $\mathrm{SiF}_{4}$. Therefore, the $\mathrm{F}$ lines can be used for etch stop detection.

\subsection{Mass spectrometry (MS)}

A residual gas analyzer/mass spectrometer (MKS Vision2000c) was applied near the process chamber exhaust exit [13]. The position of the MS orifice is about $10 \mathrm{~cm}$ away from the outer edge of the RF electrode. The RGA consists of a quadrupole mass spectrometer and can detect masses up to 300 amu. A special orifice system is mounted in front of the MS enabling measurements at pressures up to $1333 \mathrm{~Pa}$ (10 Torr) during deposition as well as during chamber cleaning $\left(\mathrm{NF}_{3}\right.$ plasma etching). We use only a range up to $90 \mathrm{amu}$ to increase the time resolution during measurements (about $0.5-3 \mathrm{~s}$ depending on accuracy). Most of the characteristic fingerprints of interesting atoms and molecules can be found in this range. MS provides only relative densities and the measured peaks are often ambiguous, i.e. they can originate from more than one detected species. Figure 5 shows mass spectra measured during a-Si:H and $\mu \mathrm{c}-\mathrm{Si}: \mathrm{H}$ deposition. Both are very similar apart from the difference in the $\mathrm{H}_{2} / \mathrm{SiH}_{4}$ ratio, which originates from the process gas ratio. In the bottom of Figure 5 a mass spectrum is shown measured during $\mathrm{Ar} / \mathrm{NF}_{3}$ plasma etch with characteristic fingerprints of etch radicals $(\mathrm{F})$ and molecules $\left(\mathrm{NF}_{x}\right)$ and etch products $\left(\mathrm{HF}, \mathrm{SiF}_{x}\right)$. The $\mathrm{SiF}_{3}$ signal detected during deposition is a residue in the RGA originating from the $\mathrm{NF}_{3}$ plasma etch, which is performed directly before each deposition process. RGA can detect a very broad range of stable atoms and molecules and is very useful for measurements of the gas composition. A disadvantage is the

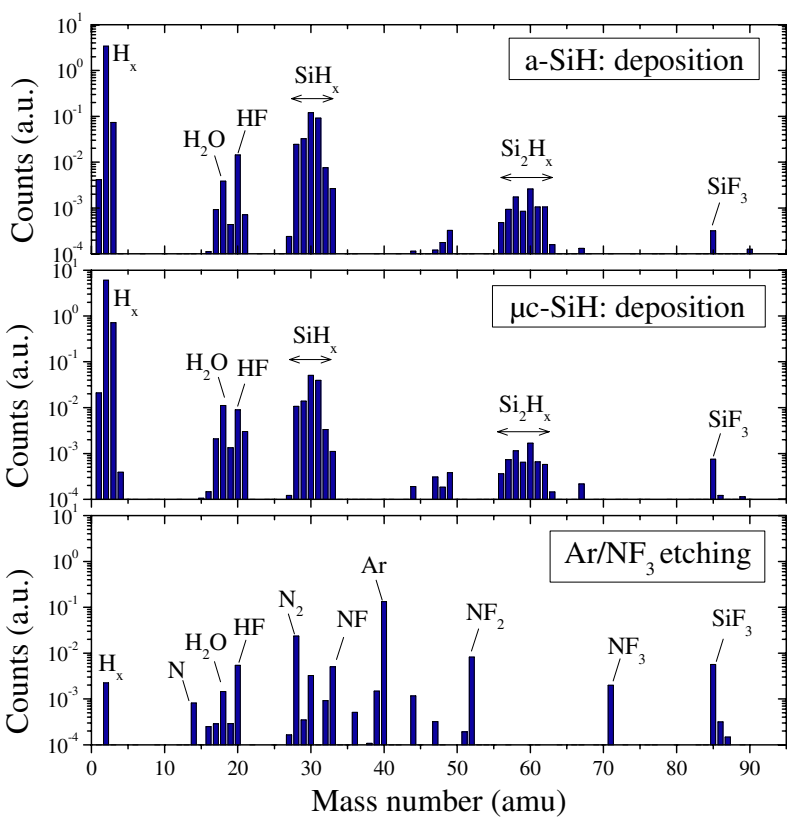

Fig. 5. Mass spectra measured during typical a-Si:H and $\mu \mathrm{c}-\mathrm{Si}: \mathrm{H}$ deposition (top and middle) and during $\mathrm{Ar} / \mathrm{NF}_{3}$ plasma chamber clean (bottom).

impact of measurement history, e.g. a long residence of fluorine in the spectrometer, and the lower time resolution compared to OES.

\subsection{Non-linear extended electron dynamics (NEED)}

The RF plasma properties were measured by means of NEED, a plasma sensor provided by Plasmetrex GmbH, which is based on self-excited electron resonance spectroscopy (SEERS) [31]. With this technique resonance effects in capacitively coupled RF plasmas are detected, which occur due to an exchange between the kinetic energy of the electrons in the plasma bulk and the electric field energy in the plasma sheaths. Strong non-linear currentvoltage characteristics within the sheaths (see equivalent circuit in Fig. 6) lead to the generation of higher harmonics, which can be measured in the displacement current at the chamber wall (see measured raw data example in Fig. 6). The sensor head can be implemented as a simple isolated metal plate at the chamber wall. Because the $\mathrm{RF}$ displacement current is not influenced by any thin film coating on the sensor head, the sensor operates under PECVD conditions as well as during $\mathrm{NF}_{3}$ plasma chamber cleaning without drift in time.

NEED is based on a 3D fluid model for the isothermal plasma electrons, describing the RF current and potential in the plasma including a non-linear model of the boundary sheath, which result in two parameters. First, the normalized plasma resistivity $\chi$, which is equal to $\nu_{\text {eff }} \times \omega_{\text {gen }} /$ $\omega_{e}^{2}$, with the effective electron collision rate $\nu_{\text {eff }}$, the $R F$ generator frequency $\omega_{\text {gen }}$ and the electron plasma frequency $\omega_{e}$. The latter is generally defined as $\omega_{e}^{2}=n_{e} \times e^{2} /$ $\left(m_{e} \times \varepsilon_{0}\right)$, with the electron density $n_{e}$, the elementary 

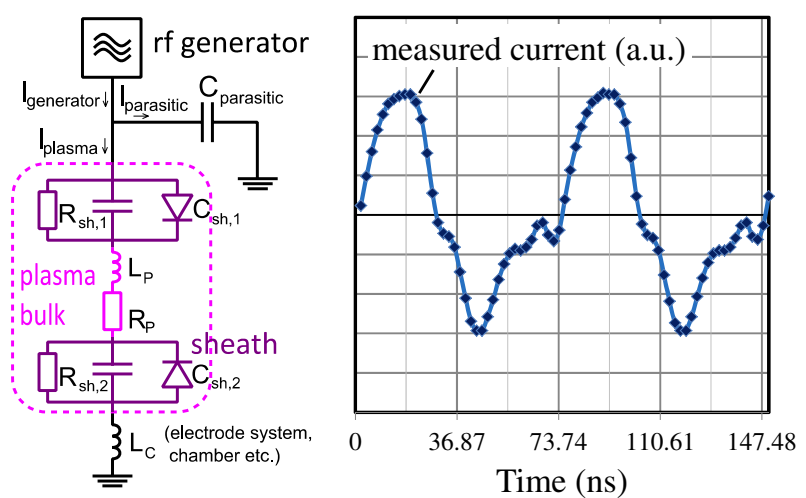

Fig. 6. Left: Scheme of the RF equivalent circuit used in the NEED model. The plasma part is marked by a dotted line. Right: Example of an electric current distorted by higher harmonics measured by NEED during one $13.56 \mathrm{MHz}$ RF cycle.

charge $e$, the electron mass $m_{e}$ and the vacuum permittivity $\varepsilon_{0}$. Therefore, $\chi$ is directly proportional to $\nu_{\text {eff }} / n_{e}$. The second parameter is the resonance frequency $f_{0}$, which comprises the inertia effect of the chamber (mainly the inductance of the movable substrate holder) and the inertia effect of the plasma electrons, both at the RF scale, (compare Fig. 6). $f_{0}$ is equal to $\left(2 \pi \sqrt{\left(L_{P}+L_{C}\right) C_{S}}\right)^{-1}$ with the plasma inductance $L_{P}$, the sheath capacitance $C_{S}$ and the inductance $L_{C}$ of the chamber/substrate holder. $L_{P}$ is equal to $m_{e} l_{p l}\left(e^{2} n_{e} A\right)^{-1}$ with the plasma bulk thickness $l_{p l}$ and the electrode area $A$. For our reactor geometry $L_{p}$ has a value in the order of $100 \mathrm{nH}$, assuming an electron density of $10^{14} \mathrm{~m}^{-3}$. The sheath capacitance $C_{S}=\frac{\epsilon_{0} A}{s_{t o t}}$ is determined by the area of the electrodes $A$ and the total sheath thickness $s_{t o t}$. The value for $L_{C}$ depends also on the position of the moveable susceptor. The exact value is unknown for our reactor, but has values in the range of $0.1-1 \mu \mathrm{H}$ and is, therefore, in the same order or even larger than $L_{p}$. Thus, only in case of sufficient grounding of the substrate holder also the plasma density can be provided directly, while in case of larger PECVD reactors $f_{0}$ is strongly influenced by $L_{C}$. Nevertheless, $\chi$ and $f_{0}$ are two basic plasma properties valuable for plasma process monitoring.

\section{Results and discussion}

In Sections 3.1 and 3.2 will be shown how the substrate temperature and the substrate surface material influence the plasma physics and chemistry. Even small changes can be detected by sensitive in situ diagnostics. In Section 3.3 we will show how a plasma itself can be used for diagnostics by a technique called etch product detection in a $\mathrm{H}_{2}$ etch plasma, and how this technique is applied to the detection of the phase transition in a-Si:H/ $\mu$ c-Si:H deposition. The last Section 3.4 deals with the influence of the chamber wall condition on the material properties of deposited doped $\mu \mathrm{c}-\mathrm{SiO}_{x}: \mathrm{H}$ layers and how it affects fill factor and open circuit voltage of a-Si:H single junction cells.

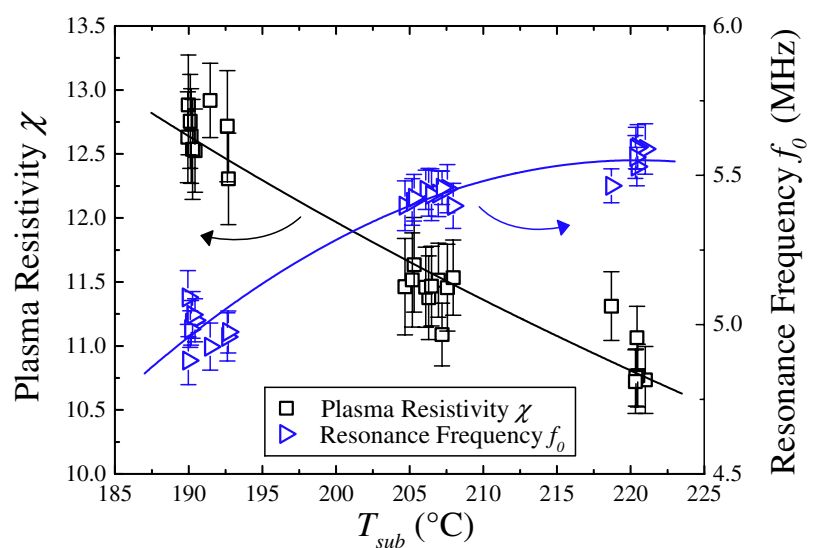

Fig. 7. Plasma resistivity and resonance frequency measured by NEED during 25 a-Si:H depositions at substrate temperatures 190,205 and $220{ }^{\circ} \mathrm{C}$.

\subsection{Influence of the substrate temperature}

Figure 7 shows $\chi$ and $f_{0}$ measured during the deposition of 25 intrinsic a-Si:H layers at substrate temperatures between $190^{\circ} \mathrm{C}$ and $220^{\circ} \mathrm{C}$, while all other process parameters are constant $(40 \mathrm{~W}, 330 \mathrm{~Pa})$. The data show strong correlations with the substrate temperature $T_{\text {sub }}$, which has been varied between $190{ }^{\circ} \mathrm{C}$ and $220{ }^{\circ} \mathrm{C}$. The substrate temperature is directly influencing the gas temperature of the plasma. With the gas temperature changes the gas density and, thus, the electron collision frequency. In this process window, $\chi$ is directly proportional to $1 / T_{\text {sub }}$ according to the ideal gas law. On the other hand, the change in the gas density is changing the bulk property of the plasma, which also leads to the change in the resonance frequency via a change of the electron energy distribution and finally the electron density. NEED proves to be very sensitive: a change in the thermodynamic temperature of only about $6 \%$ leads to a $18 \%$ change in $\chi$ and a $9 \%$ change in $f_{0}$.

Here we can also validate our initial estimation of the electron density. The collision rate $\nu$ (for momentum transfer) can be estimated to be $4 \times 10^{9} /(100 \mathrm{~Pa} \mathrm{~s})$ for both, $\mathrm{Ar}$ and $\mathrm{H}_{2}$ [32]. For a typical process pressure of $330 \mathrm{~Pa}$, one can estimate $\nu$ to be about $1.3 \times 10^{10} \mathrm{~s}^{-1}$. With $\chi=\nu_{\text {eff }} \times \omega_{\text {gen }} / \omega_{e}^{2}=10$ as shown in Figure 7 , the electron density can be estimated to be $4 \times 10^{13} \mathrm{~m}^{-3}$. This is a typical value for an electronegative plasma and in agreement to the assumption in Section 2.3.

\subsection{Influence of surface material}

The condition of the surfaces surrounding the plasma has a strong influence on the plasma chemistry. Molecules and atoms are released from these surfaces, e.g. RF electrode and chamber walls, back into the gas phase by surface etching and by the association of ions and radicals at the surface forming new gas phase molecules [25, 26]. These new molecules and atoms are a source in addition 


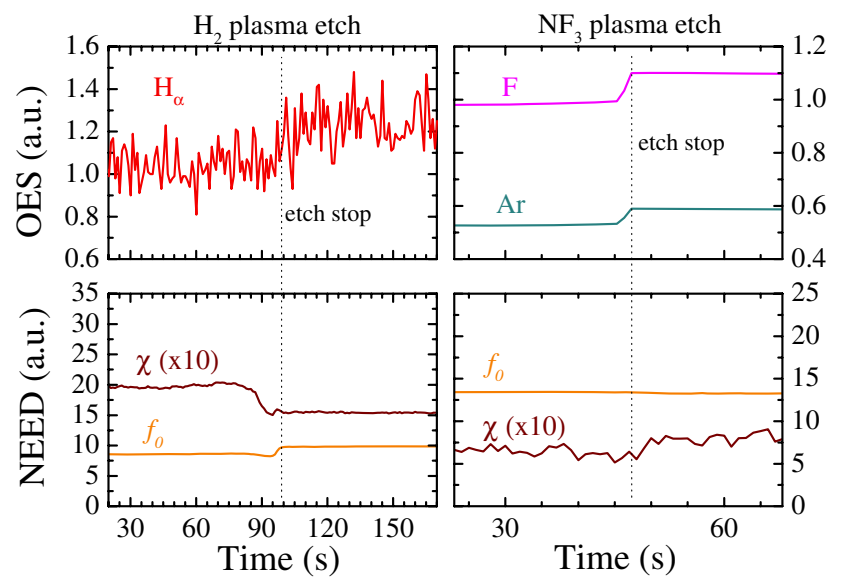

Fig. 8. Optical emission (top) and NEED (bottom) data measured during the etching of a $20 \mathrm{~nm}$ a-Si:H layer in a $\mathrm{H}_{2}$ plasma (left) and of a $50 \mathrm{~nm}$ a-Si:H layer in an $\mathrm{Ar} / \mathrm{NF}_{3}$ plasma (right).

to the process gas and, thereby, change the plasma chemistry. The impact of surfaces to the plasma chemistry can be demonstrated in a simple experiment. A glass substrate covered with a $20 \mathrm{~nm}$ a-Si:H layer was exposed to a $\mathrm{H}_{2}$ plasma in a previously cleaned reactor. The OES and NEED signals measured in this plasma are shown in the left part of Figure 8. The $\mathrm{H}_{\alpha}$ emission, as well as $\chi$ and $f_{0}$ measured by NEED are constant during the $\mathrm{H}_{2}$ plasma, but only until the a-Si:H layer is fully etched away by the $\mathrm{H}_{2}$ plasma after about $100 \mathrm{~s}$. The etch stop is clearly visible as a step in the measured signals. The etch product are $\mathrm{SiH}_{4}$ molecules. This etching results in a $\mathrm{SiH}_{4}$ concentration in the reactor similar to a case where the $\mathrm{SiH}_{4}$ flow rate is set to $3.8 \mathrm{sccm}$, a value calculated using the etch rate $(0.2 \mathrm{~nm} / \mathrm{s})$, layer density and area. This additional flow of $\mathrm{SiH}_{4}$ into the plasma gas phase is strongly changing the plasma chemistry. The change is most pronounced in the plasma resistivity $\chi$ measured by NEED, as it will be explained in more detail in Section 3.3.

Another example is the $\mathrm{NF}_{3} /$ Ar plasma etch for chamber cleaning. The right part of Figure 8 shows the $\mathrm{F}$ and Ar emission (OES) and $\chi$ and $f_{0}$ measured by NEED during a $\mathrm{NF}_{3} / \mathrm{Ar}$ plasma etching a $50 \mathrm{~nm}$ a-Si:H layer. The etch rate is much faster $(1.1 \mathrm{~nm} / \mathrm{s})$ and the equivalent gas flow rate of the etch product is $20 \mathrm{sccm}$ (of $\mathrm{SiF}_{4}$ in this case). Again, the etch stop is clearly visible, but here only in the OES data. The NEED values $\chi$ and $f_{0}$, measures for the electron density and collision rate, remain unaffected. This points out the different plasma chemistries in the two types of etching plasmas. More insight would be given by applying a collisional-radiative model, which is beyond the scope of our work.

\subsection{Plasma-surface interaction during a-Si:H/ $\mathrm{Hc}-\mathrm{Si}: \mathrm{H}$ deposition}

PECVD of $\mu \mathrm{c}-\mathrm{Si}: \mathrm{H}$ thin films using $13.56 \mathrm{MHz}$ $\mathrm{RF}$ discharges is usually performed with $\mathrm{SiH}_{4}$ strongly diluted in $\mathrm{H}_{2}$ gas under high-pressure-high-power (hphP)

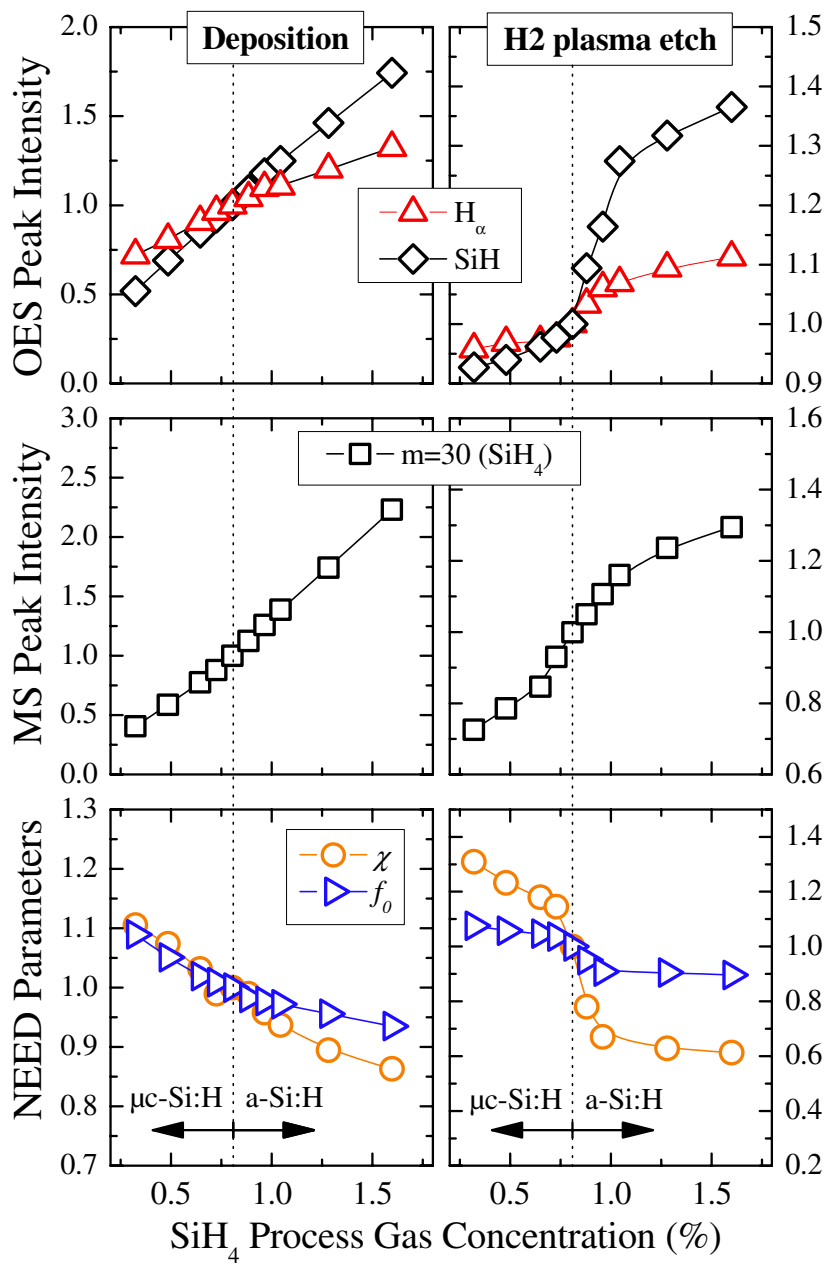

Fig. 9. OES, MS and NEED data measured during $\mu \mathrm{c}-\mathrm{Si}: \mathrm{H}$ deposition (left) and subsequent $\mathrm{H}_{2}$ plasma etching (right). The $\mu \mathrm{c}-\mathrm{Si}: \mathrm{H} \leftrightarrow \mathrm{a}-\mathrm{Si}: \mathrm{H}$ phase transition is indicated with a dotted line at $0.81 \%$ and all curves are normalized to their values at $0.81 \%$.

conditions $[4,5,7,16,33]$, i.e. the deposition under higher chamber pressures and RF powers resulting in a high $\mathrm{SiH}_{4}$ process gas depletion. In our PECVD system for sufficient layer quality and uniformity over large electrode areas the hphP process regime requires high total gas flows and a high hydrogen dilution of the process gas resulting in very low $\mathrm{SiH}_{4}$ concentrations in the order of $1 \%$ [8]. Lower $\mathrm{SiH}_{4}$ concentrations lead to $\mu \mathrm{c}-\mathrm{Si}: \mathrm{H}$ material growth, while higher $\mathrm{SiH}_{4}$ concentrations lead to amorphous growth. Best solar cells are achieved at $\mu \mathrm{c}-\mathrm{Si}: \mathrm{H}$ growth very close to the phase transition to a-Si:H growth $[16,17]$. The process window is very small, requiring stable and reproducible process conditions and/or active process monitoring and control $[8,17,34]$. The impact of the $\mathrm{SiH}_{4}$ concentration on the plasma properties during the deposition process is shown in the left part of Figure 9. The concentration was varied between $0.32 \%$ and $1.6 \%$, where the phase transition is at $0.81 \%$ (with $6160 \mathrm{sccm} \mathrm{H}_{2}$ flow and $1200 \mathrm{~Pa}$ pressure). The optical emission of the $\mathrm{H}_{\alpha}$ line and the $\mathrm{SiH}$ band (top part of Fig. 9) is proportional to the 
O. Gabriel et al.: Plasma monitoring and PECVD process control in thin film silicon-based solar cell manufacturing

Table 2. Influence of chamber condition on the Raman crystallinity and refractive index at $632 \mathrm{~nm}$ of deposited $\mu \mathrm{c}-\mathrm{SiO} x: \mathrm{H}$ $p$ - and $n$-layers.

\begin{tabular}{ccccc}
\hline \multirow{2}{*}{$\begin{array}{c}\text { Chamber conditioning } \\
\text { layer material }\end{array}$} & \multicolumn{2}{c}{$\mu \mathrm{c}-\mathrm{SiO}_{x}: \mathrm{H}$} & $p$-layer & \multicolumn{2}{c}{$\mu \mathrm{c}-\mathrm{SiO}$ : $: \mathrm{H}$-layer } \\
\cline { 2 - 5 } & Raman $F_{c}(\%)$ & $n @ 632 \mathrm{~nm}$ & Raman $F_{c}(\%)$ & $n$ @ 632 nm \\
\hline $\mathrm{a}-\mathrm{Si}: \mathrm{H}$ & 55.3 & 3.30 & 28.1 & 2.51 \\
$\mu \mathrm{c}-\mathrm{SiO}_{x}: \mathrm{H}$ & 51.4 & 3.26 & 26.7 & 2.42 \\
\hline
\end{tabular}

$\mathrm{SiH}_{4}$ concentration in the plasma, with the $\mathrm{SiH}$ emission increasing slightly faster than the $\mathrm{H}_{\alpha}$ emission. The density of $\mathrm{SiH}_{4}$ molecules in the chamber was measured by MS at mass number 30 (middle part of Fig. 9). The increase of $\mathrm{SiH}$ radicals is due to the increase of the $\mathrm{SiH}_{4}$ density in the plasma, because $\mathrm{SiH}$ is a direct dissociation product of the $\mathrm{SiH}_{4}$ process gas. The simultaneous increase of the $\mathrm{H}_{\alpha}$ emission indicates an increase in the electron density $n_{e}$, which leads directly to an increase in the production of excited $\mathrm{H}$ atoms by electron collisions with ground state $\mathrm{H}$. This increase in $n_{e}$ results from different ionization energy thresholds $E_{i o n}, t h$ of process gas molecules and their direct products: while $E_{i o n}, t h$ is equal to $15.4 \mathrm{eV}$ and $13.6 \mathrm{eV}$ for $\mathrm{H}_{2}$ and $\mathrm{H}$ [35], respectively, $E_{\text {ion, }, \mathrm{th}}$ is lower for $\mathrm{SiH}_{4}(11.0 \mathrm{eV})$ and even lower for its radicals $\mathrm{SiH}_{3}, \mathrm{SiH}_{2}, \mathrm{SiH}$ and $\mathrm{Si}$ (8.0, 8.2, 7.9, and $8.2 \mathrm{eV})$ [36]. Therefore, the increasing $\mathrm{SiH}_{4}$ concentration leads to an increase in the electron density in the plasma by enhanced ionization processes. This is confirmed by the measured plasma resistivity $\chi$, which decreases reciprocally with the electron density (bottom part of Fig. 9). Even small changes in the $\mathrm{SiH}_{4}$ gas flow strongly influence the measured plasma properties. However, the measured values change only linearly and do not show any indication at which $\mathrm{SiH}_{4}$ concentration the $\mu$ c-Si:H $\leftrightarrow$ a-Si:H phase transition occurs.

The right part of Figure 9 shows data measured during $\mathrm{H}_{2}$ plasma etch steps (each of $45 \mathrm{~s}$ duration, $500 \mathrm{~W}$, $1200 \mathrm{~Pa}, 6000 \mathrm{sccm} \mathrm{H}_{2}$ ), which were performed directly after each of the deposition shown in the left part of Figure 9. The data is plotted over the $\mathrm{SiH}_{4}$ concentration of the preceding deposition step. This technique called etch product detection was proposed by Dingemans et al. [17] and is used to detect the phase transition in thin film silicon deposited in a $\mathrm{SiH}_{4}$ gas flow variation series. The measured data show a clear non-linear behavior: the $\mathrm{H}_{2}$ plasma etch leads to an increased amount of etch products (primarily in the form of $\mathrm{SiH}_{4}$ molecules) due to an enhanced etching of the previously deposited film on substrate, RF electrode, and chamber walls, because a-Si:H is etched more easily by hydrogen radicals than $\mu \mathrm{c}-\mathrm{Si}: \mathrm{H}$ material [17]. Additionally to previously measured $\mathrm{SiH}$ emissions [17] we also found the optical emission of other lines to be dependent on the crystallinity of the etched material, shown for the $\mathrm{H}_{\alpha}$ line in Figure 9 (top right). As indicated by the $\mathrm{SiH}$ signal and here substantiated by mass spectrometry, the amount of etched silicon material is responsible for the s-like shape of the curves with $\mathrm{SiH}_{4}$ as the main etch product. Clearly visible is the trend and the s-shape also in the NEED data curves, where $\chi$ and $f_{0}$ decrease with increasing electron density resulting from increasing $\mathrm{SiH}_{4}$ concentrations in the gas phase.

\subsection{Impact of chamber wall condition}

In previous sections it was shown how surfaces (be it reactor walls or substrate) can influence the plasma chemistry. Vice versa, any change in the plasma has an impact on the thin film growths process. Therefore, the material properties of a deposited thin film layer depend on the pre-conditioning of the chamber wall. Since the start of a PECVD process usually determines the interface region of two sequential layers, the chamber conditioning has also a large impact on the performance of the resulting solar cell device. We found this dependence to be strongest for the deposition of microcrystalline material, strongly influenced by the equilibrium of deposition and etching processes as described in Sections 3.2 and 3.3. The development of proper chamber conditioning layers is an important part of the whole optimization of PECVD processes for solar cell manufacturing.

Any effect on the start of a PECVD process is strongest in case of the deposition of the thin doped $p$ - and $n$-layers, because the total deposition time is in the order of only one minute, which is much shorter than the deposition time for $i$-layers. The $p$ - and $n$-layers in our a-Si:H $/ \mu \mathrm{c}-\mathrm{Si}: \mathrm{H}$ tandem solar cells are made from doped $\mu \mathrm{c}-\mathrm{SiO}_{x}: \mathrm{H}$ material. As compared to $\mu \mathrm{c}-\mathrm{Si}: \mathrm{H}$ such layers are deposited with extremely low $\mathrm{SiH}_{4}$ concentrations below 1\% [13]. To reveal the impact of the conditioning layer on the material quality, we deposited $100 \mathrm{~nm} p$ - and $n$-type $\mu \mathrm{c}-\mathrm{SiO}_{x}: \mathrm{H}$ layers on glass substrates, each in two different runs: one in a chamber conditioned with an a-Si:H layer and one conditioned with a $\mu \mathrm{c}-\mathrm{SiO}_{x}: \mathrm{H}$ layer. The crystallinity $F_{c}$ measured by Raman spectroscopy and the refractive index $n$ at $632 \mathrm{~nm}$ measured by a photo-spectrometer [13] for the $p$ - and $n$-layers are listed in Table 2 . The resulting values depend on the type of the conditioning layer: both, the $p$ - and the $n$-layer, have a lower crystallinity if deposited in a chamber conditioned with a $\mu \mathrm{c}-\mathrm{SiO}_{x}: \mathrm{H}$ layer compared to the chamber with a-Si:H conditioning. With $F_{c}$ also the refractive index $n$ at $632 \mathrm{~nm}$ decreases slightly. This seems to be in contrast to the findings in Section 3.3, where an a-Si:H layer is etched faster than a $\mu \mathrm{c}-\mathrm{Si}: \mathrm{H}$ layer and the additional $\mathrm{SiH}_{4}$ originating from the etch process should result in the deposition of more amorphous material. However, the additional $\mathrm{SiH}_{4}$ also results in a change in the $\mathrm{SiH}_{4} / \mathrm{CO}_{2}$ process gas ratio, which determines $F_{c}$ and $n[10,11,13]$. Thus, for $\mu \mathrm{c}-\mathrm{SiO}_{x}: \mathrm{H}$ deposition the decrease in $F_{c}$ and $n$ can be explained by a decrease in $\mathrm{SiH}_{4} / \mathrm{CO}_{2}$ ratio in the plasma gas phase at PECVD start by the change from an a-Si:H to a $\mu \mathrm{c}-\mathrm{SiO}_{x}: \mathrm{H}$ conditioning layers.

The last example is about the influence of the conditioning layer material on the $p$-layer of $p$ - $i$ - $n$ solar cells 
Table 3. Influence of chamber condition on the (initial) $I-V$ characteristics of a-Si:H $p-i-n$ single junction cells deposited on $\mathrm{ZnO}: \mathrm{Al}$ front TCO. Data is averaged over $601-\mathrm{cm}^{2}$ solar cells.

\begin{tabular}{ccccc}
\hline $\begin{array}{c}\text { Chamber conditioning } \\
\text { layer material }\end{array}$ & $\begin{array}{c}J_{s c} \\
\left(\mathrm{~mA} / \mathrm{cm}^{2}\right)\end{array}$ & $\begin{array}{c}V_{o c} \\
(\mathrm{mV})\end{array}$ & $\begin{array}{c}F F \\
(\%)\end{array}$ & $\begin{array}{c}\eta \\
(\%)\end{array}$ \\
\hline$p$-type a-Si:H & $14.5 \pm 0.1$ & $912 \pm 7$ & $68 \pm 2$ & $9.0 \pm 0.3$ \\
$p$-type $\mu \mathrm{c}-\mathrm{Si}: \mathrm{H}$ & $14.5 \pm 0.1$ & $925 \pm 6$ & $69 \pm 2$ & $9.3 \pm 0.3$ \\
\hline
\end{tabular}

and, thereby, on the performance of the resulting solar cell device. The $p-i$ - $n$ layer stack was deposited on textured $\mathrm{ZnO}: \mathrm{Al}$ front $\mathrm{TCO}$ and finished by a $\mathrm{ZnO}: \mathrm{Al} / \mathrm{Ag}$ back reflector/contact. The $p$ - $i$ - $n$ layers are the same as used for top cells in our standard tandem cell device on $\mathrm{ZnO}: \mathrm{Al}\left[37\right.$, i.e. the $p$-layer is made from $\mu \mathrm{c}-\mathrm{Si}_{\mathrm{O}} \mathrm{O}_{x}: \mathrm{H}$ material. Prior to the $p$-layer deposition the PECVD chamber was conditioned in two ways: the deposition of $p$-type a-Si:H and $p$-type $\mu \mathrm{c}$-Si:H material. The chamber conditioning influences the performance of the resulting solar cell device. The resulting $I-V$ parameters measured under AM 1.5 illumination are listed in Table 3. While the short circuit current density $J_{s c}$ remains unaffected, the open circuit voltage $V_{o c}$ and the fill factor $F F$ are increased by the application of the $\mu \mathrm{c}-\mathrm{Si}: \mathrm{H}$ conditioning layer, resulting in an increase in solar cell efficiency about $0.3 \%$ absolute.

We applied the in situ diagnostics to the PECVD of the $p$-layers for these two different chamber conditionings. The PECVD recipe starts with a $30 \mathrm{~s}$ Ar plasma treatment to clean the $\mathrm{ZnO}: \mathrm{Al}$ surface e.g. from $\mathrm{H}_{2} \mathrm{O}$ molecules. Then follows the deposition of a very thin $p$-type $\mu \mathrm{c}$-Si:H seed layer and then the $p$-type $\mu \mathrm{c}-\mathrm{SiO}_{x}: \mathrm{H}$ layer. The in situ data measured during Ar treatment and seed layer deposition is shown in Figure 10. The impact of the chamber conditioning material on the plasma chemistry is clearly visible. During the Ar plasma the $\mathrm{Si}$ and $\mathrm{SiH}$ signals measured by OES are about a factor two lower in case of $\mu \mathrm{c}-\mathrm{Si}: \mathrm{H}$ conditioning. Both signals arise from etch products from the conditioning layer in form of $\mathrm{SiH}_{x}$ molecules. The $\mathrm{SiH}_{4}$ signal measured at $m=30$ by mass spectrometry is below the MS detection limit, indicating that the OES signals do not originate from $\mathrm{SiH}_{4}$ but from $\mathrm{SiH}_{x}(x=0-3)$ radicals. Again, NEED proves to be very sensitive, because the plasma resistivity $\chi$ and resonance frequency $f_{0}$ are strongly affected by the additional $\mathrm{SiH}_{x}$ in the plasma. This is even visible during the $\mu \mathrm{c}-\mathrm{Si}: \mathrm{H}$ seed layer deposition, which is performed after pumping and re-fill of the chamber with process gas. Even then, the plasma resistivity is slightly lower in case of a $\mu \mathrm{c}-\mathrm{Si}: \mathrm{H}$ conditioning layer, while OES and MS signals show no influence on the material of the conditioning layer. Therefore, the Ar plasma leads to a change on the $\mathrm{ZnO}: \mathrm{Al}$ surface, probably by re-deposition of Si material etched from the chamber wall. A similar effect was previously reported by Wanka et al. [30]: the re-deposition of $\mathrm{SiO}_{x}$ material on a TCO coated substrate during a pure $\mathrm{CO}_{2}$ plasma treatment in a process chamber conditioned by an a-Si:H layer. In our case, the re-deposited material on the $\mathrm{ZnO}$ influences the start of the seed layer deposition. This chamber history effect is covered by the deposition of the seed layer
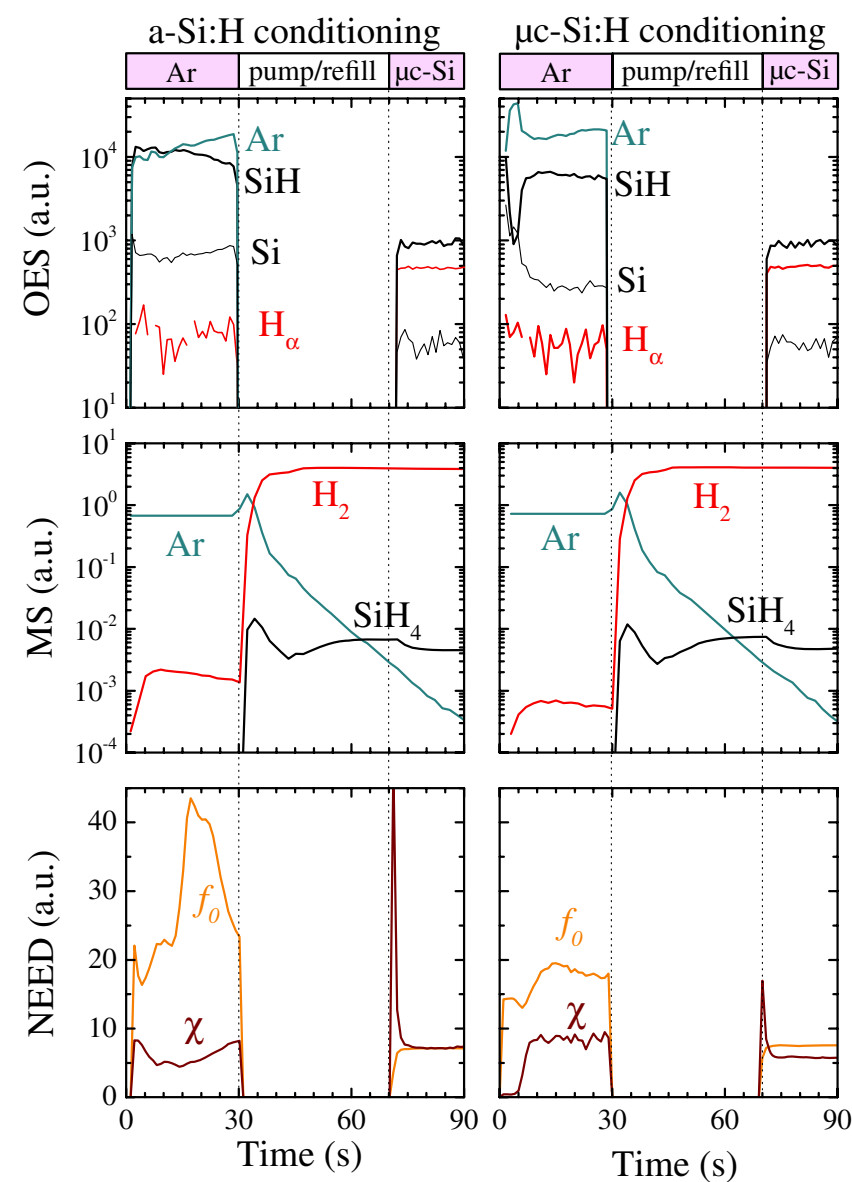

Fig. 10. OES (top), MS (middle) and NEED (bottom) data measured in situ during Ar plasma treatment and $\mu \mathrm{c}$-Si- $p$-layer deposition. Left: a-Si:H chamber conditioning, right: $\mu \mathrm{c}-\mathrm{Si}: \mathrm{H}$ chamber conditioning.

on substrate, electrode and chamber walls. The following thicker $p$-type $\mu c-\mathrm{SiO}_{x}: \mathrm{H}$ layer is not influenced by the chamber wall conditioning anymore. This explains also the equal $J_{s c}$ values in Table 3 . The influence of the conditioning layer material is only on the $\mathrm{TCO} / p$ interface region, which affects only $F F$ and $V_{o c}$.

\section{Summary}

In summary, the growth of a-Si:H, $\mu \mathrm{c}-\mathrm{Si}: \mathrm{H}$ and $\mu \mathrm{c}-\mathrm{SiO}_{x}: \mathrm{H}$ thin films by PECVD were monitored by means of three complementary plasma diagnostics: OES, MS and NEED. Next to the process parameters such as chamber pressure, RF power and process gas composition, the substrate surface temperature and surface material properties influence the plasma chemistry as well and, thus, the PECVD process and properties of the resulting thin films. We showed how in situ plasma diagnostics adds valuable data for fast and effective process development on the PECVD process. Especially NEED is a very sensitive technique, which can detect even very small changes in the plasma gas phase and substrate/chamber 
O. Gabriel et al.: Plasma monitoring and PECVD process control in thin film silicon-based solar cell manufacturing

wall temperature. Finally, we demonstrated the impact of the chamber wall conditioning on the properties of $\mu \mathrm{c}-\mathrm{SiO}_{x}: \mathrm{H}$ material and how the chamber conditioning influence the $p$-layer for $p$ - $i$ - $n$ solar cells and, ultimately, their electrical performance.

The authors thank M. Zelt for technical assistance. This work was supported by the Federal Ministry of Education and Research (BMBF), by the Federal Ministry of Environment (BMU) and the state government of Berlin (SENBWF) in the framework of the program "Spitzenforschung und Innovation in den Neuen Ländern" (Grant No. 03IS2151) and the "SiliziumDS12plus" project (Grant No. 0325317C).

\section{References}

1. J. Perrin, J. Schmitt, C. Hollenstein, A. Howling, L. Sansonnens, Plasma Phys. Control. Fusion 42, 353 (2000)

2. A. Descoeudres, L. Barraud, R. Bartlome, G. Choong, S.D. Wolf, F. Zicarelli, C. Ballif, Appl. Phys. Lett. 97, 183505 (2010)

3. T. Mishima, M. Taguchi, H. Sakata, E. Maruyama, Sol. Energy Mater. Sol. Cells 95, 18 (2011)

4. M. Kondo, M. Fukawa, L. Guo, A. Matsuda, J. Non-Cryst. Solids 266, 84 (2000)

5. A.V. Shah, H. Schade, M. Vanecek, J. Meier, E. VallatSauvain, N. Wyrsch, U. Kroll, C. Droz, J. Bailat, Prog. Photovolt.: Res. Appl. 12, 113 (2004)

6. K. Yamamoto, A. Nakajima, M. Yoshimi, T. Sawada, S. Fukuda, T. Suezaki, M. Ichikawa, Y. Koi, M. Goto, T. Meguro, T. Matsuda, M. Kondo, T. Sasaki, Y. Tawada, Sol. Energy 77, 939 (2004)

7. B. Rech, T. Repmann, M.N. van den Donker, M. Berginski, T. Kilper, J. Hüpkes, S. Calnan, H. Stiebig, S. Wieder, Thin Solid Films 511, 548 (2006)

8. M.N. van den Donker, B. Rech, R. Schmitz, J. Klomfass, G. Dingemans, F. Finger, L. Houben, W.M.M. Kessels, M.C.M. van de Sanden, J. Mater. Res. 22, 1767 (2007)

9. S. Inthisang, K. Sriprapha, S. Miyajima, A. Yamada, M. Konagai, Jpn J. Appl. Phys. 48, 2402 (2009)

10. P. Cuony, D.T.L. Alexander, I. Perez-Wurfl, M. Despeisse, G. Bugnon, M. Boccard, T. Söderström, A. Hessler-Wyser, C. Hébert, C. Ballif, Adv. Mater. 24, 1182 (2012)

11. A. Lambertz, F. Finger, B. Holländer, J. Rath, R. Schropp, J. Non-Cryst. Solids 358, 1962 (2012)

12. K. Schwanitz, S. Klein, T. Stolley, M. Rohde, D. Severin R. Trassl, Sol. Energy Mater. Sol. Cells 105, 187 (2012)

13. S. Kirner, O. Gabriel, B. Stannowski, B. Rech, R Schlatmann, Appl. Phys. Lett. 102, 051906 (2013)
14. D. Mataras, S. Cavadias, D. Rapakoulias, J. Appl. Phys. 66, 119 (1989)

15. U. Fantz, Plasma Phys. Control. Fusion 40, 1035 (1998)

16. B. Strahm, A.A. Howling, L. Sansonnens, C. Hollenstein, Plasma Sources Sci. Technol. 16, 80 (2007)

17. G. Dingemans, M.N. van den Donker, A. Gordijn, W.M.M. Kessels, M.C.M. van de Sanden, Appl. Phys. Lett. 91, 161902 (2007)

18. H. Nomura, K. Akimoto, A. Kono, T. Goto, J. Phys. D 28, 1977 (1995)

19. A. Howling, B. Strahm, C. Hollenstein, Thin Solid Films $\mathbf{5 1 7}, 6218$ (2009)

20. N. Itabashi, K. Kato, N. Nishiwaki, T. Goto, C. Yamada, E. Hirota, Jpn J. Appl. Phys. 27, L1565 (1988)

21. R. Bartlome, A. Feltrin, C. Ballif, Appl. Phys. Lett. 94, 201501 (2009)

22. V. Lisovskiy, J.-P. Booth, K. Landry, D. Douai, V. Cassagne, V. Yegorenkov, Appl. Phys. 40, 6631 (2007)

23. S. Nunomura, I. Yoshida, M. Kondo, Appl. Phys. Lett. 94, $071502(2009)$

24. J.P.M. Hoefnagels, Y. Barrell, W.M.M. Kessels, M.C.M. van de Sanden, J. Appl. Phys. 96, 4094 (2004)

25. M. Cacciatore, M. Rutigliano, Plasma Sources Sci. Technol. 18, 023002 (2009)

26. D.C. Schram, Plasma Sources Sci. Technol. 18, 014003 (2009)

27. P. Pernet, M. Goetz, H. Keppner, A. Shah, Mater. Res. Soc. Symp. Proc. 452, 889 (1997)

28. A. Gordijn, J. Rath, R. Schropp, J. Appl. Phys. 95, 8290 (2004)

29. T. Merdzhanova, J. Woerdenweber, T. Zimmermann, U. Zastrow, A. Flikweert, H. Stiebig, W. Beyer, A. Gordijn, Sol. Energy Mater. Sol. Cells 98, 146 (2012)

30. H. Wanka, G. Bilger, M. Schubert, Appl. Surf. Sci. 93, 339 (1996)

31. M. Klick, J. Appl. Phys. 79, 3445 (1996)

32. Y.P. Raizer, V.I. Kisin, J.E. Allen, Gas discharge physics (Springer, Berlin, 1991)

33. Y. Mai, S. Klein, R. Carius, J. Wolff, A. Lambertz, F. Finger, X. Geng, J. Appl. Phys. 97, 114913 (2005)

34. T. Kilper, M.N. van den Donker, R. Carius, B. Rech, G. Bräuer, T. Repmann, Thin Solid Films 516, 4633 (2008)

35. R.K. Janev, D. Reiter, U. Samm, Collision Processes in Low-Temperature Hydrogen Plasmas, Berichte des Forschungszentrums Jülich 4038 (Forschungszentrum Jülich, Jülich, 2003)

36. R.K. Janev, D. Reiter, Contrib. Plasma Phys. 43, 401 (2003)

37. B. Stannowski, O. Gabriel, S. Calnan, T. Frijnts, A. Heidelberg, S. Neubert, S. Kirner, S. Ring, M. Zelt, B. Rau, J.-H. Zollondz, H. Bloeß, R. Schlatmann, B. Rech, Sol. Energy Mater. Sol. Cells 119, 196 (2013)

Cite this article as: Onno Gabriel, Simon Kirner, Michael Klick, Bernd Stannowski, Rutger Schlatmann, Plasma monitoring and PECVD process control in thin film silicon-based solar cell manufacturing, EPJ Photovoltaics 5, 55202 (2014). 